\title{
$-172-$
}

nation faite en consideration d'un mariage annulé, devient caduque. Giorgi "Teoria delle obligazioni, volume $3 .^{\circ} \mathrm{n} .^{\circ} 44 \mathrm{I}$, quasi nos mesmos termos adopta a doutrina; e que ella não repugna ao direito patrio deprehende-se do disposto na Ordenação Liv. 4." tit $6_{3}$, pr., que reputa perfeita e acabada-para o effeito de não poder ser revogada, tão sómente a doação *pura e simplesmente feita sem alguma condição ou causa passada, presente e futura.» Ora, tratando-se, quanto aos bens patrimoniaes da ex-princezas d'uma verdadeira doação modal, feita para fim determinado (o explendor do throno) parece que, cessando a causa do contracto, torna-se ella caduca revertendo ao patrimonio do Estado os bens doados. «Sublata causa tollitur effectus».

A logica é irrecusavel, tanto mais quando serve de interprete ao direito e á liberdade.

São Paulo, I 5 de Janeiro de I 892.--Brazilio dos Santos.-- De accordo com os motivos. - Herculnno de Freitas.

\section{PROJECTO DO CODIGO CIVIL}

A Congregação dos lentes da Faculdade de Direito de S. Paulo, em cumprimento de pedido do Governo federal, elegeu o Snr. Dr. Antonio Dino da Costa Bueno, em uma das sessões do corrente anuo para fazer parte da commissão encarregada de dar parecer sobre o projecto do Codigo Civil Brazileiro, organisado pelo Snr. Dr. Antonio Coelho Rodrigues.

Em desempenho desse encargo, o Snr. Dr. Antonio Dino, relator daquella commissão, elaborou o seguinte parecer:

A commissão incumbida de examinar e dar parecer sobre o projecto do Codigo Civil Brazileiro 


\section{$-173$}

apresentado ao Governo pelo Dr. Antonio Coelho Rodrigues, vem desempenhar-se da missão de que foi encarregada.

I. Por contracto de 12 de Julho de I89o, celebrado com o governo, obrigou-se o Dr. Antonio Coelho Rodrigues a redigir e entregar, no. prazo de tres annos, um projecto de Codigo Civil com uma parte geral e outra especial.

A parte geral será subdividida, diz o contracto, em tres livros:

I" das pessoas;

$2^{\circ}$ dos bens;

$3^{\circ}$ dos actos e dos factos juridicos.

A parte especial será tambem subdividida, continúa o contracto, em quatro livros:

$I^{\circ}$ dos direitos da familia;

$2^{\circ}$ dos direitos reaes;

$3^{\prime \prime}$ dos direitos pessoaes;

$4^{\circ}$ do concurso de clireitos.

Comprehendendo este ultimo livro cinco secções:

$\mathrm{I}^{\text {a }}$ das successões, testamentaria e legitima;

$2^{a}$ das instituiçōes de credito real e de seguro:

$3^{a}$ do concurso dos credores e da preferencia dos creditos ;

$4^{\mathrm{a}}$, das prescripçð̃es;

$5^{\mathrm{a}}$, da restituição "in integrum», se não parecer preferivel substituir este remedio extraordinario por outro ordinario ou supprimi-lo.

$\mathrm{Na}$ elaboração do projecto, obrigou-se a consolidar quanto possivel o direito vigente, reformando o que conviesse alterar, substituir ou supprimir, accrescentando o que faltasse á legislaçào actual, de accordo com a experiencia das nações civilisadas, e com as necessidades da situação do Brazil.

O projecto apresentado e sujeito á consideração da commissão, além de um projecto da lei preliminar 


\section{$-174-$}

do Codigo Civil, contém as duas partes determinadas no contracto: a parte geral e a parte especial.

A parte geral está dividida em tres livros:

I"), das pessoas;

$2^{\circ}$, dos bens:

$3^{\circ}$, dos factos e actos juridicos.

A parte especial está dividida em quatro livros:

$1^{\circ}$, das obrigações ;

$2^{\circ}$, da posse, da propriedade e dos outros direitos reaes ;

$3^{\circ}$, do direito da familia;

$4^{\circ}$, do direito das successões.

Em •disposições addicionaes transitorias» propõe o autor a acceitação e publicação do projecto, como Codigo Civil da Republica, para sobre elle se receberem informações officiaes e particulares, á vista das quaes e dos progressos realisados em outros paizes e utilisaveis no Brazil, e da jurisprudencia dos tribunaes da União e dos Estados, formule uma commissão de codificação geral, nomeada desde já, a sua proposta de revisăo do novo codigo.

II. Não é arbitraria a distribuição das materias de direito civil, e, sobre este ponto, a commissão é de parecer que deve ser adoptada a classificação que Heise e Thibaut iniciárão na Allemanha, conhecida entre os juristas com a denominação de classificação allemã.

O direito é dividido em duas partes, uma geral e outra especial.

A parte geral comprehende as seguintes subdivisões :

$1^{a}$, das pessoas;

$2^{\mathrm{a}}$, das cousas ;

$3^{\mathrm{a}}$, dos actos juridicos.

A parte especial comprehende as seguinites:

$\mathrm{I}^{\mathrm{a}}$, direito das cousas; 


\section{$--175-$}

$2^{\text {a }}$, direito das obrigaçōes;

$3^{\mathrm{a}}$, direito da familia;

$4^{\mathrm{a}}$, direito das successnes.

Não é perfeita esta classificação: tem sido ao menos consagrada pelos competentes, e a commissão de jurisconsultos que em I88 I deu parecer sobre os "Apontamentos para o projecto do Codigo Civil», apresentado pelo Dr. Joaquim Felicio dos Santos, da qual tambem fez parte o illustre autor do actual projecto, a acceitou e propoz para ser seguida.

III. Classificar as materias ou traçar o plano geral a seguir-se, é ainda muito pouco quando se trata de elaborar um Codigo Civil: a questão de methodo na execução inteira do plano é de interesse capital em trabalho desta natureza, quer se attenda ao modo pelo qual devão ser tratadas as partes do plano geral, quer ao modo de serem apresentadas e desenvolvidas as diversas instituições do direito.

O direito é uma necessidade real da vida: por natureza deve ser e é effectivamente realisado.

Diversas causas podem embaraçar-lhe a realisação, perturbando o sereno e integral desenvolvimento da vida: por isso quie elle tem em sua natureza a necessidade de ser realisado, triumpha, afinal, de todos os embaraços e preenche a funcção a que é destinado.

A realisação mais ou menos prompta do direito tanto importa com a satisfação mais ou menos prompta de uma necessidade da vida.

O codigo que é o direito, e é tambem a fórma do direito, deve reunir em si as condições que delle dependem, tendentes a garantir, e de modo prompto, facil e seguro, aquella realização.

Entre as condições, que dão realizabilidade ao direito, ha duas especialmente confiadas ao cuidado do legislador: uma relativa ao proprio direito - a 


\section{$-176 \ldots$}

opportunidade; a outra relativa a fórma -- a perfeição technica.

O direito constituido deve ser opportuno: isto quer dizer que o direito deve estar em relação directa com o estado social a que tem de ser applicado. Se não guarda com elle conformidade, se fere as tradições populares, se magoa o sentimento juridico nacional, com certeza encontrará na realização os maiores tropeços; é o individuo que se rebella contra elle, é o juiz que procura illudir-lhe a execução, sāo principalmente as forças historicas productoras do direito que lhe levantão a resistencia mais tenaz.

A opportunidade, porém, por si só, não dá realizabilidade ao direito: elle não poderá ser executado se não fôr conhecido, e não será conhecido se não for perceptivel.

A perceptibilidade do direito depende essencialmente da fórma que se lhe dê; a fórma imperfeita é uma sombra que occulta o direito; a fórma perfeita é uma revelação que o impõe.

Se a fórma é imperfeita, o direito é obscuro, duvidoso, incerto; terá uma realização demorada.

Se a fórma é perfeita, o direito se nos apresenta de modo visivel: o espirito o contempla e quasi que o apalpa ; comprehende-o em sua existencia unica, e na existencia de cada um dos corpos que o compõem ; apercebe as relações que em seus corpos mantém entre si e com o todo; domina-o em summa e pela realização integra-lhe a natureza.

Como dar ao direito essa perfeição technica, como constitui-lo ou organisa-lo, como executar o plano geral adoptado, taes são os problemas a se resolverem em trabalhos desta natureza.

O legislador tem diante de si todas as regras que presidem ou devem presidir, ás multiplas relações 


\section{$-177-$}

da vida civil, e é com este material que o plano adoptado tem de ser executado, já na parte geral, já na parte especial.

Não preencherá a missão legislativa aquelle que formular e apresentar todas essas regras, ainda que distribuindo-as com certo methodo pelas diversas instituições de direito; por certo não organisará o direito quem assim lhe dér uma fórma tão tosca e inelegante, tão grosseira e tão pesada, em que innumeras serāo as regras e muitas as repetições.

São tão estreitas as relações que prendem as diversas instituições em que o direito funcciona e tal a natureza ou composição intima do direito subjectivamente considerado, em todas as manifestações, no tempo e no espaço, sempre o mesmo em seus elementos fundamentaes, que a contemplação das regras, que em torno dellas se agrupão, produz o conhecimento de que em todas ellas, ao lado de elementos especiaes existem elementos geraes, que são sempre os mesmos em algumas, em um grupo dellas ou mesmo em todas.

A analyse encarrega-se de fazer a separação desses elementos geraes, e o valor delles, e a influencia que exercem na formação, e portanto no conhecimento das regras especiaes, relativas a cada uma das instituições juridicas, encarregão-se de destinar-lhe, sem contestação, a parte geral do plano em que o direito tem de ser accommodado.

A parte geral ficará assim composta de verdadeiros elementos logicos do direito, capazes, senão de abrir, ao menos de facilitar ao espirito o conhecimento da parte especial, onde devem estar as regras peculiares ás diversas instituições, por meio das quaes exerce o direito a função que lhe é dada.

Não é isso novidade nà technica do direitò. 
A commissão, já supra mencionada, que deu parecer sobre os Apontamentos, do Dr. Joaquin Felicio dos Santos, criticando a parte geral dos mencionados apontamentos escreveu "conviria porventura supprimir o titulo preliminar e limitar a parte geral, quando muito ás maximas consagradas pelas nações cultas, aos principios de verdadeira doutrina scientifica, posto não geralmente praticados, observando-se com as precisas restrições o eventual collidir do direito privado interno e externo e mormente consignar as regras concernentes á condição e capacidade juridica das pessoas."

A parte especial refere-se particularmente á construcção do direito civil.

A commissão distingue a construç̧ão scientifica da construcção legislativa: a primeira compete ao theorico, á jurisprudencia scientifica, só a segunda compete ao legislador ou elaborador do Codigo Civil.

A competencia legislativa é limitada, como se vio pela necessaria equação entre a disposição do direito e o estado social do povo; o elaborador do codigo tem diante de si, e preparado, todo o material sobre que tem de operar, fornecido parte pelo sentimento juridico nacional, consagrado ou não em textos positivos, parte, pela jurisprudencia scientifica, que não é só nacional, mas sim como a sciencia universal, incumbida naturalmente da construcção theorica do direito.

Ainda ahi deve o legislador examinar a materia com cuidado para só acceitar as conquistas reaes da jurisprudencia scientifica, distinguindo, separando e rejeitando as concepções theoricas de juristas isolados, mesmo que tenhão recebido a sancção de alguma autoridade legislativa.

Posto que seja assim limitada a materia sobre a qual o legislador tem de operar, não é facil, antes 


\section{$-179-$}

eriçada de serias difficuldades, à tarefa legislativa, principalmente quando tem de ser desempenhada sobre todo o corpo do direito civil.

Descriminar as instituições, agrupar em torno de cada uma dellas as regras que lhe sejão relativas, reduzir a quantidade dessas regras e melhorar-lhes a qualidade, dar-lhes uma fórma adequada, distribui-las methodicamente, e finalmente, distribuir as instituições juridicas assim compostas, conforme o systema adoptado, taes são as operações de que ha de sempre depender o bom exito da elaboração de um codigo civil.

$\mathrm{Na}$ discriminação está o reconhecimento das instituições: estas, verdadeiros corpos juridicos, segundo a feliz expressão de Ihering, têm as suas condições de existencia independente, e estas condições devem ser bem verificadas, afim de que não possa aquella qualidade ser usurpada, indebitamente augmentado, com a usurpação, o quadro das instituições, falseada, portanto, ou perturbada a obra legislativa.

As instituições, reconhecidas, devem ser meditadámente consideradas, em seu principio e em seu fim, em sua natureza ou elementos fundamentaes, cada um de per si, isoladamente, todas nas relações que tenhão ou possão ter umas com as outras.

Só deste exame póde derivar o conhecimento exacto, a descriminação perfeita; como se faz mister para tarefa tão escabrosa.

Sem elle, não poderá o quadro das instituições ser expurgado de creações, reaes, é verdade, mas que ainda não reunem em si as condiçôes de uma existencia independente.

Sem elle, não terão as instituições a distribuição que a natureza lhes assignala, e algumas, por terem certos caracteres communs, serão confundidas, não obstante a especialidade que as distinga, difficultan- 
do-se-lhes, por esta fórma, a comprehensão ou o conhecimento, abrindo-se a porta a erros de applicação, quebrando-se a economia do direito, impossibilitando-se a fundação da unidade systematica, que é requisito essencial a todo o direito bem constituido.

Depois das instituições, vem a consideração das regras, a carne e o sangue do direito, no dizer da jurisprudencia allemã. Pois que o direito é uma das faces da vida, as regras são tantas quantas as relações, que a vida tem creado entre os homens.

Comprehende-se que para cada relação não póde ser conservada uma regra especial, para cada caso uma disposição, e a parte geral, mesmo como foi comprehendida, já tem conseguido, pela generalisação, a eliminação de muitas dellas.

Ainda ha porém, a respeito das regras ou das disposições da parte especial, alguma cousa confiada á tarefa legislativa. Umas existem realmente no corpo das leis, outras têm a sua existencia latente, com base no sentimento juridico nacional, outras são apenas preconisadas pela experiencia dos povos policiados; devem todas ser cuidadosamente examinadas, confrontadas e apprehendidas em suas relações, fundidas se fôr possivel, dando-se-lhes uma fórma geral, mediante uma expressão mais intensa, modificadas, alteradas ou substituidas conforme a experiencia dos povos cultos.

Melhoradas na qualidade e reduzidas na quantidade, deve-se-lhes dar uma fórma clara, precisa, rigorosa, technica, em a qual só se vejão os vocabulos consagrados e sómente elles, e sempre elles, quando se queira designar a mesma cousa ou a mesma idéa.

A ninguem é dado duvidar do valor da linguagem para a expressão do pensamento; isto que na pratica geral da vida é uma verdade commum, em materia scientifica ou de legislação assume as propor- 


\section{$-181-$}

ções de uma verdade necessaria, sem a qual, nem a sciencia, nem a legislação podem ter vida.

IV. Passando a considerar o projecto, á luz dos principios acima assentados, a commissão começa por notar que no desdobramento da parte especial abandonou elle completamente o plano e a terminologia do contracto.

Começa pelo «Direito das obrigações» que pelo contracto com a denominação de "Direitos pessoaes» devia ficar em terceiro lugar; alterou a denominação do segundo livro que passou a ser " da posse, da propriedade e dos outros direitos reaes»; passou para o terceiro livro o "Direito da familia", que pelo contracto devia estar em primeiro lugar; finalmente no fundo e na fórma modificou completamente o $4^{\circ}$ livro, que, supprimida a restituição «integrum", e distribuidas pelos outros livros as materias não indicadas no contracto, não se occupou com o "concurso de direitos", mas foi exclusivamente dado ao "direito das successões. »

A este proposito a commissão cumpre o dever de reconhecer que, salva a intrusão da prescripção na parte geral considerada como facto juridico, o plano do projecto é sem duvida superior ao contracto; pois que é o mesmo da classificação allemã, a que a commissão já acima referio-se, modificada apenas pela anteposição do direito das obrigações ao direito das cousas.

Não obstante ter-se assim apartado do contracto e invertido os dous primeiros termos da classificação allemã, o illustre autor do projecto não julgou-se obrigado a apresentar exposição escripta em que indicasse os motivos do seu procedimento, e, na unica conferencia que teve com a commissão, nenhuma razão scientifica adduzio em fundamento da inversão da classificação de Thibaut. 


\section{$-182-$}

E’ verdade que ao projecto do Codigo Civil Allemão apresentado ao chanceller do Imperio ein I 877 , e até ao presente sujeito a estudo de commissão nomeada pelo Governo, iniciou na classificação a antecipação do direito das obrigações ao direito das cousas, mas a commissão acredita que esta anteposição foi principalmente determinada por uma razão toda peculiar áquelle paiz.

E' sabido que a unificação da legislação civil, decretada na Allemanha por modificação constitucional de 1873 , não pôde ainda até ao presente ser levacla a effeito pela opposição que lhe fazem os diversos Estados allemães. E' certo que deste I 8 7 I esses Estados acceitárão o direito das obrigações como materia federal, commum a tocios elles: em uma legislação ou em um codigo que quer ser o mesmo para todos os Estados federados, nada mais logico do que darse o primeiro lugar ao direito das obrigações, que já é commum a todos, e que por isso mesmo serve para demonstrar-lhes a possibilidade e a necessidade da unificação.

V. A parte geral do plano foi executada de modo muito diverso daquelle pelo qual a commissão comprehende.

Não foram só os elementos geraes do direito apurados pelo processo analytico acima referidos, que ahi tiverão collocação: de envolta com elles o projecto contém materias inteiramente estranhas á competencia de um codigo civil e materias pertencentes á parte especial.

O Tit. $3^{\circ}$ do Liv. $\mathrm{I}^{\circ}$ inscripto Dos brazileiros e estrangeiros» não só occupa um logar indevido na parte geral, como usurpa mesmo um logar no quadro do direito civil.

A determinação da nacionalidade é assumpto que só compete ao direito politico ou constitucional: as- 


\section{$-183$}

sim o comprehendeu já a Constituição do Imperio, em 1824 , assim o entendeu tambem a Constituição da Republica, de 24 de Fevereiro de 189 I.

Ao direito civil compete determinar a personalidade, quer a physica, quer a juridica, pois esta é a qualidade sobre que elle se funda, assim como a nacionalidade é a qualidade sobre que se funda o direito politico; este só compete ao nacional, como aquelle só compete á pessoa, qualquer que seja a nacionalidade.

Esta é a concepção scientifica dos tempos modernos, já actualmente consagrada na legislação dos povos civilisados: para não citar senão um, o codigo chileno, en vez das tantas disposições de que se compõe esse titulo da parte geral do projecto, com uma simplicidade e uma elegancia admiraveis, diz apenas o seguinte no art. 57: "La lei no reconoce diferencia entre el Chileno i el estranjeiro encuanto a la adquisicion i goce de los derechos civiles que regla este Codigo"

O Cap. $5^{\circ}$ do Tit. $3^{\circ}$ do Liv. $2^{\circ}$, tratando dos bens em relação aos seus proprietarios, contém disposições minuciosas relativamente á demarcação, divisão, distribuição e aforamento de terrenos pertencentes á União, na zona da futura Capital Federal, aos Estados e aos municipios, chegando ao ponto de tratar das dimensões dos lotes e das edificações naquelles que tiverem sido aforados, (arts. I 35 e I 36 ): nem deve um codigo civil tratar de tal assumpto, nem póde o nosso attentas as disposições constitucionaes actuaes, dispôr de bens pertencentes aos Estados e aos municipios.

Os registros de nascimento, obitos e naturalisação occupão tambem um largo espaço da parte geral, pois foram-lhe destinados os capitulos $2^{\circ}, 3^{\circ}, 4^{\circ} \mathrm{e}$ $5^{\circ}$, do Tit. $1^{\circ}$, do Liv. $3^{\circ}$. 
A commissão é de parecer que o projecto não devêra ter passado das disposições primeiras sobre este assumpto; uma lei especial poderia trata-lo com maior desenvolvimento, e finalmente os regulamentos completarião a obra da lei com as minucias das disposições relativas; a não ser assim ter-se-ha a anomalia de estar o codigo civil a dispôr sobre solemnidades, fórmas e dimensões dos livros de registro, sobre o modo de escrevê-los e até sobre as . horas do serviço.

Tambem a prescripção, ao vêr da commissão, não é materia que deva e possa ser considerada na parte geral, onde o projecto a collocou (arts. 214 e seguintes) tratando-a, já na face acquisitiva como modo de adquirir a propriedade, já na extinctiva, como modo de extinç̧ão dos direitos pessoaes, nāo deve e não póde porque, como instituição toda especial, está subordinada a disposições peculiares do direito que lhe determinão a existencia, que lhe assignalão as condições da vida, que the definem as especies, discriminando em cada uma os requisitos a serem preenchidos, e finalmente que lhe estatuem os effeitos.

E' bem de ver-se que disposições assim relativas a uma creação especial não podem ser collocadas ao lado daquellas que só apresentão os elementos que pelo seu caracter de generalidade devem ser considerados como os elementos logicos do direito, pois que são exactamente os que, combinando-se, entrão na formação das regras por meio das quaes elle funcciona.

Quanto aos elementos geraes de direito, materia propria que essa parte do projecto contém, a commissão tem o dever de observar que o modo pelo qual são apresentados deixa muito a desejar, quando se trata de averiguar se esta parte geral preencheu 
realmente o intuito que se collima com a divisão das materias do codigo.

A pessoalidade physica e juridica e a capacidade civil são tratadas de modo tal que antes confundem do que preparão o espirito de quem queira entrar no conhecimento do direito.

A pessoa juridica é apresentada em pedaços, parte no Cap. $\mathrm{I}^{\circ}$ do Tit. $2^{\circ}$ do Liv. ${ }^{\circ}$ arts. 7 a 10 , parte no Cap. $2^{\circ}$, arts. I 8 a 29 , parte no Cap. $3^{\circ}$, arts. 30 a 40 , parte no Cap. $5^{\circ}$ do Tit. $2^{\circ}$ do Liv. $3^{n}$, arts. I 90 a 207 , parte em artigos esparsos, como por exemplo os arts. 222,223 e outros, que poderião ser citados.

Confrontando-se disposições (arts. 7, i 8 e 30 ) parece que a fundação não é pessoa juridica civilmente constituida e sim uma nova creação que nem é a pessoa physica, nem é a pessoa juridica.

Contemplando-se o art. I 8 elle nos revela $\left(\$ 3^{\circ}\right)$ uma pessoa juridica differente das outras, autinomica com a idéa juridica de todos que procurão conhecer o direito, relativamente a essa classe de pessoas: é uma pessoa juridica que, em relação aos seus proprios bens, admitte direitos identicos nas pessoas dos individuos que a compõem materialmente.

A capacidade civil é tratada de um modo injusto e com terminologia nova, não superior á antiga e inexacta para o proprio projecto: é bastante lembrar a tutela marital do $\$ 6^{\circ}$ do art. I4, e a incapacidade do preso em carcere privado ou em cumprimento de sentença, com o que pretende o projecto não só trazer, como ainda ampliar no nosso meio juridico os effeitos da antiga servidão da pena dos romanos.

Iguaes observações poderião ser feitas pela commissão, relativamente aos outros dous livros da parte geral: faltando-lhe o tempo que isso demandaria, limita-se a dizer que elles não escapão á conside- 


\section{$-186$}

ração a uma apresentada de modo geral, isto é, não satisfazem aos intuitos da divisão do plano do codigo.

VI. A parte especial do projecto tambem não escapou do defeito na distribuição das materias.

De lado muitas disposições de processo que indebitamente occupão lugar no quadro das materias e que se não podem encontrar justificação na razão geral das cousas, são hoje principalmente condemnadas pelo actual regimen politico do paiz, que a cada um dos Estados, de que se compõe a União Brazileira, deu competencia para regular as materias do processo, a commissão encontra entre as materias proprias do quadro uma distribuição irregular, que está muito longe de se conformar com o organismo vivo do direito conforme a construcção da jurisprudencia scientifica; do qual o codigo não deve ser menos do que a imagem reflexa.

Já a commissão teve o cuidado de accentuar a a necessidade de um perfeito reconhecimento, de uma exacta discriminação de todas as instituiç̧ões para que no codigo seja cada uma dellas aquillo que realmente é no direito conforme o tem determinado o sentimento nacional, a legislação existente e a doutrina scientifica.

A collocação inexacta, a classificação erronea, o defeito da determinação dos elementos fundamentaes ou caracteristicos, a confusão das instituições juridicas, são forças que produzem necessariamente o erro no conhecimento, na applicação das disposições, embaração a realisação do direito, perturbão o mecanismo da vida e prejudição a economia social.

Foi já por defeito na apreciação exacta das materias que o projecto tratou da nacionalidade, como materia pertencente ao quadro do direito civil, e da prescripção, como materia que pudesse ser alinhada no plano da parte geral. 
Mas não se limitárão a estes os fructos da apreciação inexacta, e a commissão vai apontar os que lhe parecerão mais salientes:

I. ' A locação, tratando-se de cousas, é apresentada pelo projecto como o contracto pelo qual «um dos contrahentes se obriga a ceder, durante um tempo determinado ou não, o uso ou o goso de uma cousa ao outro que se obriga a pagar-lhe um preço proporcional ao tempo". O projecto apresenta-a nestes termos como um direito puramente pessoal (se obriga a ceder), e nessa conformidade consigna varias disposições, como principalmente a do $\$ 3^{\circ}$ do art. 717 .

No art. 7 Io apresenta-a como "direito de servidão"; no art. 7 I I confunde-a com a emphyteuse, equiparando o locatario ao emphyteuta, e conferindo-lhe direitos que só a emphyteuse contém; no art. 736 apresenta-a como um direito real especial, e confirma esta apresentação com os arts. I $700 \leqslant 2^{\circ}$ I 8 I I e seguintes; nos capitulos $4^{0}$ e $6^{0}$ deste mesmo titulo, arts. 789 e 818 e seguintes, apresenta-a como sociedade, considerando como locações a parceria agricola e a pecuaria, que, por natureza, são verdadeiras sociedades; finalmente, no Tit. I 8 do Liv. $3^{0}$, art. $235^{2}$ e seguintes, tratando especialmente da locação de serviços domesticos apresenta-a como uma relação de familia.

Vê-se por ahi que a locação é, para o projecto, direito pessoal, direito real especial, direito de servidão, direito de emphyteuse, direito de sociedade e, finalmente, direito de familia; e conclue-se que não é possivel comprehender-se a natureza de uma instituição, que assim é apresentada com qualidades tão diversas, cada uma das quaes altera-lhe substancialmente a natureza intima. 
2. O contracto de edição é tratado pelo projecto como uma figura especial de direito. $\mathrm{O}$ art. 843 o institue do seguinte modo: "Considera-se contracto de edição aquelle pelo qual o autor de uma obra scientifica, litteraria ou artistica, ou seu legitimo representante, se obriga a entrega-la a um editor, que, por seu turno, se obriga a reproduzi-la em um numero mais ou menos consideravel de exemplares e a espalha-los pelo publico.»

Não é possivel por esta apresentação chegar-se a conhecer qual o carateristico do novo contracto, nem ao menos qual o motivo teleologico que o domina, e esta impossibilidade se accentua em face do art. 86I, em que o projecto trata de uma hypothese que absolutamente não póde estar contida no art. 843 .

Da leitura, porém, dos artigos em que é tratado o contracto de edição, resulta que elle é, para o projecto, ou a venda da propriedade litteraria, ou a locação da industria ou serviços do editor, que se encarrega da impressão da obra intellectual (art. 844), ou a locação de serviço profissional (art. 86 I), a que se refere o projecto no $\$ 4^{\circ}$ do art. 766 , quando o editor por sua conta encarrega a alguem de escrever ou colleccionar um trabalho litterario.

No estado actual do nosso direito não será preciso senão recorrer, pensa a commissão, ás disposições relativas a essas instituições, salvas as clausulas que as partes entenderem convenientes á regulamentação de suas respectivas posições juridicas.

$3 .^{\circ}$ A posse está bem collocada no primeiro titulo do Livro 22 ; é por assim dizer o vestibulo do edificio dos direitos reaes; mas a commissão não póde deixar de reconhecer que o projecto não foi feliz no modo pelo qual a considerou.

A posse é para o projecto a manifestação de um poder material sobre a cousa unida á vontade do 


\section{$-189-$}

detentor exercer esse poder no seu proprio interesse (art. 1 325 ); o inquilino, o rendeiro, o locatario de uma cousa qualquer, todos que detêm em nome de outro, mesmo o detentor precario, desde que tem sobre cousa um interesse legitimo, são possuidores segundo a concepção do projecto.

Mas, porque destruir deste modo a belleza da admiravel theoria que a sabedoria juridica dos romanos tão bem soube formular, e que a doutrina scientifica até ao presente ainda não pôde alterar ? Porque desconjuntar-lhe o systema?

A commissão diz destruir a belleza da theoria e desconjuntar o systema romano, porque o projecto, nas disposições que consagrou, não conseguio subverter a idéa juridica dos romanos sobre a posse, que irrompe sempre e imponente, senão na lettra do projecto, ao menos no pensamento: ahi está no artigo 1,363 alguem que detem a cousa, por motivo legitimo, e no interesse proprio, e que não é possuidor, apezar de ser chamado possuidor; ahi está no art. I,3 18 o inquilino, possuidor de boa fé, porque a posse de boa fé, como diz o art. I,333, apenas suppõe uma tomada sem vicio e sem titulo que a justifique, e que, entretanto, no pensamento do projecto nã̃o ha de por certo fazer seus os fructos da cousa locada.

Considerando-a aqui como capaz de fundar um direito real (art. I, 355, com o qual estão de accordo os arts. 105 e I.803), com a disposição do art. 84 elimina-a do quadro dos direitos reaes. Não é possivel comprehender-se a posse considerada ao mesmo tempo como direito real e como direito pessoal; e sobre isso a commissão accrescenta que a concepção da posse como direito real é ainda um ensaio de construcção theorica, que, comquanto adoptada em alguma legislação positiva (codigo do Cantão de 


\section{$-190-$}

Zurich), não foi sanccionada pela doutrina geral, de modo a estar constituida como verdadeira construcção scientifica.

4. ${ }^{\circ} \mathrm{O}$ Tit. $5^{\circ}$ do Liv. $2^{\circ}$ inscreve-se - Das servidões, o cap. $\mathrm{I}^{\circ}$ desse titulo inscreve-se - Das servidóes prediaes: isto é o bastante para julgar-se mal do modo pelo qual o projecto considerou a materia das servidões.

A concepção scientifica da servidão apresenta-a como um onus real, constituido sobre um predio pertencente a um dono em beneficio de outro predio pertencente a dono diverso; não ha, pois, servidão que não seja predial.

A inscripção do capitulo, em vista disto, ou é pleonastica, ou é a demonstração viva de que o projecto fez da materia uma apreciação inexacta, que no desenvolvimento ha de forçosamente produzir as suas necessarias consequencias.

Effectivamete a commissão nota que o projecto, apartando-se da concepção scientifica da servidão, foi levado a incluir neste titulo, considerando-os como servidões, o usufructo, o uso, a habitação, e até a renda constituida sobre immoveis (Caps. $2^{\circ}, 3^{\circ}$ e $4^{\circ}$ ), instituições que, se têm de commum com as servidões a natureza real, dellas se distinguem pelos carateristicos que thes dão existencia especial.

A concepção erronea, a que o projecto se abraçou, levou-o mais a não guardar fidelidade, ainda mesmo ás suas denominadas "servidões prediaes".

E' assim que, dando no art. I 543 a «servidão predial» como aquella que é "sempre estabelecida em favor de um predio sobre outro pertencente a diverso dono, que em razão della é impedido de fazer ou obrigado a tolerar alguma cousa, que aliás podèria fazer ou não soffrer", no art. I 544 dispõe "que a materia de uma servidão predial póde, por accor- 
do entre os donos dos predios, dominante e serviente, ser convertido em onus real deste em beneficio de uma determinada pessoa juridica, ou de um certo individuo ; de modo que para o projecto ha a servidão predial, que é onus entre predio e predio, mas póde haver uma "servidão predial» que seja onus entre predio e pessoa..

5." A hypotheca e a antichrese tambem não foram discriminadas pelo projecto, e a confusão destas duas instituições determinou a apresentação da antichrese no titulo destinado á hypotheca, como se a antichrese fosse hypotheca, ou se não podesse ter existencia independente delle.

$\mathrm{E}$ assim entendeu effectivamente o projecto, conforme o art. I 769 , que the revelaria o conceito, se por ventura já não fosse sufficiente o facto de considerar elle a antichrese como um capitulo da hypotheca.

Diz esse artigo:

"Quando nos termos do art. i 644 o contrato hypothecario confere o usufructo da cousa ao credor, este ficará pelo mesmo facto investido dos direitos e sujeitos ás obrigações do usufructo".

Esta disposição que ahi fica transcripta é ainda um pouco mais compromettedora: ella revela que, se o projecto começou confundindo a antichrese com a hypotheca, acabou confundindo-a com o usufructo; de sorte que para o projecto a antichrese, que não póde existir senão com a hypotheca, resume-se afi. nal no usufructo da cousa hypothecada.

Que instituição é essa que não tem existencia independente, que não tem regras que lhe sejão especiaes ?

$\mathrm{E}^{\prime}$ evidente que o projecto a si mesmo se condemna, referindo-se a uma instituição que, no seu conceito, não tem existencia juridica. 


\section{$-192-$}

$\mathrm{E}$, entretanto, é elle mesmo que acredita na existencia da instituição, e é certo que existe, e qué é distincta da hypotheca, e que tem as suas regras especiaes, e que não se confunde com o usufructo.

VII. Depois das considerações que acabão de ser feitas relativamente aos lineamentos geraes sobre que o projecto executou a parte especial do código, a commissão julga-se dispensada de descer ao exame do desenvolvimento dado ás diversas materias juridicas.

A ninguem é dado construir sobre fundamentos falsos: com tal comprehensão das instituições, o projecto não poderia ter-lhes dado o desenvolvimento completo, exacto e harmonico.

A commissão, porém, não ultimará as suas observações sobre a parte especial do projecto, sem ligeiras referencias ao direito da familia, em relação ao qual são muitas as modificações propostas ao direito vigente, umas sem razão conhecida e de difficil descobrimento, outras sem preencher o fim que lhes póde ser åttribuido.

O projecto começa apresentando a familia como uma sociedade natural e necessaria, elementar da civil e independente della nas suas relafões moraes, fundada ou constituida pelo casamento (art. I 82 I e e I $_{23}$ ); é a idéa juridica da familia.

Ahi mesmo, porém, no Cap. ${ }^{\circ}$ do Tit. $\mathrm{I}^{\circ}$ do Liv. $3,{ }^{\circ}$ onde se achão os arts. I 82 I e I 823 , a commissão encontra, como concepções diversas, cinco especies de familia, as quatro do art. 1822 (a familia natural, a familia civil, a familia legitima, à familia domestica) e a do art. I 824 em que se apresenta a familia constituida por uma só pessoa naturat.

E' facil comprehender-se que isto desvirtua completamente a idéa fundamental, e impossibilita sobre 
as relações de fámilia o regular desenvolvimento das regras respectivas.

Desta obliteração da idéa fundamental da familia proveio sem duvida o facto de permittir o projecto (art. 2, I 47), ainda depois do pai casado, o reconhecimento de filhos naturaes, que entrão a fazer parte da familia com iguaes direitos aos do filho legitimo, pois que o art. 1,826 dispõe que "a lei equipara aos legitimos os filhos naturaes reconhecidos na sua conformidade.

Desta mesma fonte proveio a confusão com que é tratada a materia relativa ao regimen do casamento (Tit. $4^{\prime \prime}$, arts. I,974 a 2,095), em vista da qual não é permittido saber-se qual seja para o projecto o chamado regimen commum ou regimen legal, isto é, aquelle que, pelo direito actual, resulta immediatamente da lei, quando os conjuges, antes do casamento, nada tenhão pactuado sobre o regimen de seus bens.

Nem sobre isto se póde dizer que tenha o projecto supprimido este regimen legal, para só adoptar o convencional, conforme conclusão autorisada pelo $\$ 5 \cdot^{\circ}$ do art. I 877 , porque ahi está o art. 1974 a dizer, não que é obrigatorio, mas que "é licito aos contrahentes» estipular em contracto anterior o regimen de casamento que queirão adoptar.

O projecto trata de dous dotes, isto é, de duas instituições diversas com o mesmo nome: uma é o dote na significação rigorosamente juridica, acceita pelo direito vigente, isto é, aquelle que constitue regimen dotal (arts. 2.016 a 2.067); a outra é creação do projecto, e vem a ser aquelle que o pai é obrigado a fazer á filha que se casa, ou a ratear, por occasião do casamento, entre a que se casa e as solteiras, se porventura a que se casa não precisa de dote (arts. 1.967 a 1.973 ). 


\section{$-194-$}

A commissão julga-se desobrigada de dizer qualquer cousa a respeito; uma creação tão extravagante não merece as honras da consideração.

A emancipação tem, para o projecto, significação muito diversa daquella que todos até aqui lhe têm attribuido.

No rigor do direito, emancipação quer dizer solução do patrio poder; emancipados são todos aquelles para os quaes se tem rompido o vinculo de subordinação ao poder do pai, sem attenção ao motivo, ou a idade e condição.

Uma expressão erronea, infelizmente adoptada em texto legislativo (art. I. $^{\circ} \$ 2 .^{\circ}$ do Codigo Commercial), deu lugar ao emprego do vocabulo em significação diversa da juridica com applicação ao menor supplementado, isto é, munido de supplemento de idade.

O projecto abandona a significação technica, adopta a que, produzida pelo erro de applicação, modifica-a um pouco, e apresenta, com o mesmo nome, creação inteiramente nova para o direito; a emancipação quer dizer capacidade para os actos de simples administração (art. 2.283).

Emancipão-se os menores que se casão, e os de I 8 annos, que, do pai, da mãi ou do conselho de familia, conseguem esta concessão; mas a capacidade que a emancipação thes confere não os livra da curatella, pois o menor que se casa fica sujeito á curatella do pai, na falta deste, se a mulher fôr maior, á da mulher, se fôr menor, á da mãi, se ambos forem menores, á de um curador nomeado pelo consetho de familia ou de tutela (art. 228).

A emancipação assim constituida, nascida de um erro na applicação da palavra, é um verdadeiro retrocesso, quando se attende ao estado actual do nosso direito, segundo o qual os menores casados e os sup- 


\section{$-195$}

plementados não estão sujeitos á curatella, são em tudo equiparados aos maiores, salva a restriçcão relativa aos bens de raiz.

A administração das pessoas e bens dos menores é extraordinariamente complicada pelas disposições do projecto (arts. 2.205 a 2.276); elle institue um protutor, entidade distincta do tutor, mas que deve existir com elle e ao lado delle; crêa um conselho de familia, um conselho de tutela, conselhos especiaes em alguns casos mais importantes, e distribuindo funcções a todas estas creações, embaraça a administração e não consegue diminuir nestes negocios a intervenção judicial.

O Tit. Io deste livro com a inscripção - -Da tutela dos incapazes e da curatella dos interdictos»vai além das disposições da parte geral (art. I 4), augmentando o numero dos interdictos e ampliando a idéa da prodigalidade, contra a tendencia do direito, em taes materias, sempre restrictiva.

VIII. A commissão vai terminar o seu trabalho.

A má comprehensão das instituições fatalmente traria comsigo não só a má distribuição das materias como o inexacto e insufficiente desenvolvimento dado ás mesmas.

Accrescentem-se a isto a lamentavel redacção ou fórma dada a quasi todas as disposições do projecto, a falta de logica na deducção das consequencias resultantes dos principios estabelecidos, as antinomias flagrantes, que são abundantes, e a conclusão será forçada: o projecto não tem as condições necessarias para ser acceito, ainda mesmo nos termos da proposta feita nas-disposições addicionaes transitorias,-como base de revisão para o futuro Codigo Civil da Republica.

E' este o parecer da commissão. 


\section{$-196-$}

A insuficiencia dos que foram incumbidos de missão tão ardua, e a escassez do tempo que lhes foi dado, justificão de sobra, aos olhos dos doutos, a grande deficiencia deste trabalho: a commissão, porém, tem a consciencia de que procurou cumprir o seu dever.

Rio de Janeiro, sala da commissão, na Secretaria da Justiça e Negocios Interiores, 27 de Julho de 1893. - Antonio José Rodrigues Torres, neto, presidente. - Antonio Dino da C. Bueno, relator.-M. do N. Machado Portella Junior.

\section{PRIMEIRO ANNO DO CURSO JURIDICO, EM 1828}

Para aqui trasladamos (I), como subsidio á historia da Faculdade de Direito de S. Paulo a lista dos estudantes matriculados em $\mathrm{r} 828$, os primeiros que iniciaram o seu curso nesta Faculdade.

I Antonio Paes de Camargo, natural da villa de Sorocaba, provincia de S. Paulo.

2 Manuel Dias de Toledo, natural da villa de Porto Feliz, provincia de S. Paulo.

3 José Antonio Pimenta Bueno, natural desta cidade de $\mathrm{S}$. Paulo.

4 José Christiano Garção Stockler, natural da villa de S. João d'El-rei, provincia de Minas Geraes.

5. Vicente Pires da Motta; natural desta cidade de S. Paulo.

6. José Fernando de Almeida, natural da cidade do Rio de Janeiro.

7. Francisco José Pinheiro Guimarães, natural da cidade do Rio de Janeiro.

8. José Ignacio Vaz Vieira, natural da cidade do Rio de Janeiro.

(1) O Farol Paulistano, n. 104, de 16 de Abril de 1828 . 